\title{
Evaluation of dysphagia risk, nutritional status and caloric intake in elderly patients with Alzheimer's
}

\author{
Vanessa Fernanda Goes ${ }^{1}$ \\ Pâmela Billig Mello-Carpes ${ }^{2}$ \\ Lilian Oliveira de Oliveira ${ }^{3}$ \\ Jaqueline Hack ${ }^{4}$ \\ Marcela Magro 4 \\ Juliana Sartori Bonini ${ }^{5}$
}

Objective: to evaluate the risk of dysphagia and its relationship with the stage of Alzheimer's Disease, as well as the relationship between the risk of dysphagia and nutritional status and caloric intake in elderly people with Alzheimer's disease. Methods: the sample consisted of 30 subjects of both genders with probable Alzheimer's disease. The stage of the disease, nutritional status, energy intake, and risk of dysphagia were assessed. Results: it was found that increased risk of dysphagia is associated with the advance in the stages of Alzheimer's disease and that even patients in the early stages of disease have a slight risk of developing dysphagia. No association was found between nutritional status and the risk of dysphagia. High levels of inadequate intake of micronutrients were also verified in the patients. Conclusion: an association between dysphagia and the development of Alzheimer's disease was found. The results indicate the need to monitor the presence of dysphagia and the micronutrient intake in patients with Alzheimer's disease.

Descriptors: Elderly Nutrition; Alzheimer Disease; Energy Intake; Vitamins; Eating Disorders; Feeding Behavior.

\footnotetext{
${ }^{1}$ Master's student, Universidade Estadual do Centro-Oeste, Guarapuava, PR, Brazil. Scholarship holder from Coordenação de Aperfeiçoamento de Pessoal de Nível Superior (CAPES).

${ }^{2}$ PhD, Adjunct Professor, Universidade Federal do Pampa, Uruguaiana, RS, Brazil.

${ }^{3}$ Doctoral student, Universidade Federal do Rio Grande do Sul, Porto Alegre, RS, Brazil. Professor, Universidade Estadual do Centro-Oeste, Guarapuava, PR, Brazil.

${ }^{4}$ Undegraduate students in Nutritional, Departamento de Nutrição, Universidade Estadual do Centro-Oeste, Guarapuava, PR, Brasil. Scholarship holder of the Scientific Initiation from Fundação Araucária de Apoio ao Desenvolvimento Científico e Tecnológico do Estado do Paraná.

${ }^{5} \mathrm{PhD}$, Adjunct Professor, Departamento de Farmácia, Universidade Estadual do Centro-Oeste, Guarapuava, PR, Brazil.
}

Corresponding Author:

Juliana Sartori Bonini

Universidade Estadual do Centro-Oeste. Departamento de Farmácia

Rua Simeão Camargo Valera de Sá, 3

Vila Carli

CEP: 85040-080, Guarapuava, PR, Brasil

E-mail: juliana.bonini@gmail.com
Copyright $\odot 2014$ Revista Latino-Americana de Enfermagem This is an Open Access article distributed under the terms of the Creative Commons Attribution Non-Commercial License (CC BY-NC).

This license lets others distribute, remix, tweak, and build upon your work non-commercially, and although their new works must also acknowledge you and be non-commercial, they don't have to license their derivative works on the same terms. 


\section{Introduction}

Population aging is now a worldwide phenomenon and a permanent trend. The number of elderly people increased by $2.4 \%$ between 1950 and 2005, much faster than the total population, the growth rate of which was 1.2 per cent between 2000 and 2005. The number of people aged 65 and over in 2010 was 7.3 per cent of the world population and is expected to exceed the number of people under age five in a little more than a decade ${ }^{(1)}$.

Aging is accompanied by several functional changes, including neurobiological ones. These changes in the central nervous system include atrophy of neuronal groups with dilation of ridges and ventricles, reduced synaptic activity, decreased plasticity, increased glial activity, accumulation of metabolic products, deposits of beta-amyloid protein, and granulovacuolar degeneration, which appear early in the medial temporal regions and spread throughout the neocortex ${ }^{(2)}$. These changes, particularly the latter, can develop into some types of dementia.

Currently over 25 million people are affected by dementia, most of whom suffer from Alzheimer's disease (AD), and about 5 million new cases of dementia occur per year ${ }^{(3)}$. The number of people with dementia is expected to double every 20 years and the prevalence of $A D$ nearly doubles every 5 years beyond the age of 65 . Hence, as it is the most prevalent progressive neurodegenerative illness worldwide, there is a need to study the pathophysiology of this disease as well as the risks and problems associated with it ${ }^{(4-5)}$.

A previous study showed that the cognitive deficits found in neurological diseases, such as $A D$, may cause interruption to the present and preparatory actions required for swallowing(6). The main alterations to swallowing found in these patients are lingual motor dysfunction, delayed triggering of the swallowing reflex, failed oral motor control of the bolus, retention of food in the vallecula and pyriform sinuses, penetration and aspiration - especially of liquids, and absent mastication(7).

This impaired swallowing can result in what is known as dysphagia, which is a common clinical manifestation in patients with Alzheimer-type dementia, affecting about $28 \%$ to $32 \%$ of these patients ${ }^{(8)}$. Swallowing disorders in patients with dementia may lead to the risk of malnutrition and death, due to low caloric intake and aspiration of food ${ }^{(7)}$. Dysphagia has also been correlated with the development of pneumonia, which is a common cause of morbidity and mortality, especially in elderly people with dementia( ${ }^{(9)}$.

Studies have also shown that $A D$ patients have a worse nutritional status when compared with a control group without dementia, with weight loss, and, often, inadequate caloric intake $\mathrm{e}^{(10-12)}$. As nutritional status is often impaired in elderly people with $A D$, nutritional care and interventions regarding mealtime difficulties are essential; it is important to note that the second aspect is relevant to the clinical nursing practice ${ }^{(13-14)}$.

Although the most significant problems of dysphagia are found in the moderate and severe stages of $A D$, there is one study that reports swallowing difficulties during the early stages of the disease ${ }^{(10)}$. This study clearly shows the increased risk of dysphagia in $A D$ patients, however, few studies have correlated dysphagia with the developmental stages of $A D$, malnutrition and food intake in these patients.

From the above arose the guiding question of this study: "What is the relationship between the stage of development of $A D$ and the risk of dysphagia and nutrition issues (nutritional status and caloric intake)?" Understanding this issue may improve measures of healthcare professionals for elderly people with dementia, including nursing professionals, who are often responsible for the care of $A D$ patients. Accordingly, the present study aimed to assess and verify the relationship between the risk of dysphagia, nutritional status, caloric intake, and the stage of Alzheimer's disease.

\section{Methods}

This was a cross sectional study that was part of a larger project. The subjects were enrolled in the Specialized Drug Delivery Program of the Brazilian Ministry of Health, and resided in Guarapuava, Paraná, Brazil. The initial sample consisted of 66 subjects, of these, 7 patients died before the beginning of the data collection, 11 changed address and were not found and 18 patients were not found at the address recorded after three attempted visits on different days of the week. Thus, the final sample consisted of 30 patients diagnosed with probable AD according to the criteria of the National Institute of Neurologic and Communicative Disorders and Stroke and the Alzheimer Disease and Related Disorders Association (NINCDS-ADRDA)(15). The mean age of the patients was $77 \pm 9.3$ years and $60 \%$ $(n=18)$ were female. The data collection took place between August and October 2011, in the homes of the elderly subjects. 
The CDR (Clinical Dementia Rating) was assessed by the researcher (a health professional trained in this respect) to classify the stage of development of $A D$ in the patients with this pathology. For each category (memory, orientation, judgment and problem solving, community affairs, home and hobbies, and personal care) a score was given - healthy/no dementia (CDR 0), questionable dementia (CDR 0.5), mild dementia (CDR $1)$, moderate dementia (CDR 2) or severe dementia (CDR 3) according to the rules established(16).

To assess the degree of dysphagia, the adapted questionnaire(17) entitled Questionnaire for Identifying Risk of Oropharyngeal Dysphasia in Elderly Patients with Dementia was used. The questionnaire addresses the following issues: the time required to complete meals; refusal of food; use of liquids during meals; tiredness when eating; remaining seated during meals; the escape of food from the corner of the mouth and the presence of food leftover after the meal; food consistency preference; forgetting to swallow; the expulsion of food from the mouth; difficulty swallowing some types of food; pain or discomfort when swallowing; frequent coughing or choking after swallowing; drowsiness after meals; presence of nasal reflux; and a history of frequent respiratory infections. From this evaluation, the dysphagia was classified as low risk ( 0 to 1 point), slight risk (2-9 points), moderate risk (10-17 points) or serious risk (18 to 25 points).

The nutritional status of the elderly subject was assessed using the Mini Nutritional Assessment (MNA)(18), in which values less than 17 characterize the individual as malnourished, between 17 and 23.5 as at risk of malnutrition, and from 23.5 to 30 as having normal nutritional status. The MNA was applied by the caregiver of the patients with CDR 2 or CDR 3.

The patients' food intake was assessed using 24hour Recall, in which the caregiver provided information about times, food/beverages, type of preparations, and quantities of food consumed within the 24 hour period prior to the interview. The quantities consumed were estimated in household measures, units or portions. All the reported food/drinks underwent dietary analysis, consisting of the energy values (kcal), and macronutrient and micronutrient content, performed using the Avanutri ${ }^{\circledR}$ version 4.0 (2010) computer program.

The values obtained for each nutrient were compared with the recommendations of the Dietary Reference Intakes - DRI, according to gender and age, as there are no specific recommendations for patients with $A D$. The appropriate percentage of each nutrient was calculated for each patient using the following formula:

Appropriate percentage $=$ quantity of nutrient taken in $(\mathrm{g} / \mathrm{mg} / \mathrm{mcg}) \div$ recommendation $(\mathrm{g} / \mathrm{mg} / \mathrm{mcg}) \times 100$.

Data are presented as mean and standard deviation for the continuous variables and frequency for the categorical variables. Statistical analysis was performed using Anova, Fisher's test and the Kruskal Wallis test with Dunn's post hoc test. The level of significance was set at $p<0.05$.

The study was approved by the Research Ethics Committee of the Universidade Estadual do CentroOeste (protocol. 026/2011). The Terms of Free Prior Informed Consent were signed by the elderly person's legal guardian.

\section{Results}

Regarding the risk of dysphagia, $13.3 \%(n=4)$ of the patients had a minimal risk, 70\% $(n=21)$ a slight risk, and $16.6 \%(n=5)$ a moderate risk. No patients were identified with a serious risk of dysphagia.

In Table 1 it can be seen that there was no statistical difference between the socio demographic variables when the sample was classified into groups according to the risk of dysphagia.

In assessing the stage of $A D$, it was found that $33.33 \%$ of the patients $(n=10)$ was in a mild stage (CDR1), 26.66\% $(n=8)$ in a moderate stage (CDR 2) and $40 \%(n=12)$ in a severe stage of the disease (CDR 3$)$.

Using the Kruskal Wallis test it was verified that there was a significant difference in the risk of dysphagia according to the stages of AD (Table $2 ; p=0.019$ ), with a difference between the mild and severe stages according to Dunn's post hoc test.

Regarding the nutritional status of the patients, the MNA showed that $30 \%(n=9)$ was malnourished, $53.3 \%(n=16)$ was at risk of malnutrition and $16.6 \%$ $(n=5)$ well nourished. Considering the nutritional status according to the MNA and the degree of risk of dysphagia (Table 3 ), it can be seen that the patients were distributed in all the degrees of dysphagia, with the largest number of patients, $40 \%(n=12)$ presenting a slight risk and also a risk of malnutrition. Thus, no differences in the risk of dysphagia among elderly people with different nutritional status (classified using the MNA; $P=0.377$; Fisher's Exact test) were found. 
Table 1 - Characteristics of the study sample according to the risk of dysphagia, Guarapuava - PR, Brazil, 2011

\begin{tabular}{|c|c|c|c|c|}
\hline & Minimum Risk $(n=4)$ & Slight Risk $(n=21)$ & Moderate Risk (n=5) & $\mathbf{p}$ \\
\hline Mean age $(\text { years) })^{\ddagger}$ & $68.0 \pm 14.7$ & $78.0 \pm 7.8$ & $78.0 \pm 8.3$ & 0.484 * \\
\hline Family income $(R \$)^{\ddagger}$ & $1893.0 \pm 1942.1$ & $2378.0 \pm 1361.7$ & $1739.0 \pm 861.3$ & $0.598^{\dagger}$ \\
\hline Schooling (years) ${ }^{\ddagger}$ & $6.7 \pm 3.8$ & $4.3 \pm 3.5$ & $5.4 \pm 4.5$ & $0.141^{\dagger}$ \\
\hline Martial status (\%) & & & & $0.686^{\dagger}$ \\
\hline Single (n [\%]) & $0(0.0)$ & $2(9.5)$ & $0(0.0)$ & \\
\hline Married (n [\%]) & $2(50.0)$ & $9(42.8)$ & $3(60.0)$ & \\
\hline Widowed (n [\%]) & $2(50.0)$ & $10(47.6)$ & $2(40.0)$ & \\
\hline
\end{tabular}

*ANOVA comparing three groups

†Fisher's Exact test comparing three groups

$\neq$ Continuous variables are presented as mean \pm SD

Table 2 - Risk of dysphagia according to the stage of Alzheimer's disease, Guarapuava, PR, Brazil, 2011

\begin{tabular}{lccc}
\hline \multirow{2}{*}{ Stage of the disease } & \multicolumn{3}{c}{ Risk of dysphagia } \\
\cline { 2 - 4 } & $\begin{array}{c}\text { Minimal Risk } \\
\mathbf{n}(\%)\end{array}$ & $\begin{array}{c}\text { Slight Risk } \\
\mathbf{n}(\%)\end{array}$ & $\begin{array}{c}\text { Moderate Risk } \\
\mathbf{n}(\%)\end{array}$ \\
\hline Mild (CDR1) & $4(100)$ & $6(28.5)$ & $0(0)$ \\
Moderate (CDR2) & $0(0)$ & $7(33.3)$ & $1(20)$ \\
Severe (CDR3) & $0(0)$ & $8(38.1)$ & $4(80)$ \\
\hline
\end{tabular}

Kruskal Wallis test: $P=0.019$, followed by Dunn's test - Mild stage vs. severe stage CDR: Clinical Dementia Rating

Table 3 - Distribution of patients with Alzheimer's disease according to the risk of dysphagia and nutritional status, Guarapuava, PR, Brazil, 2011

\begin{tabular}{|c|c|c|c|c|}
\hline \multirow{2}{*}{$\begin{array}{c}\text { Mini Nutritional } \\
\text { Assessment }\end{array}$} & \multicolumn{3}{|c|}{ Dysphagia } & \multirow[b]{2}{*}{ Tota } \\
\hline & $\begin{array}{l}\text { Minimal } \\
\text { Risk }\end{array}$ & $\begin{array}{l}\text { Slight } \\
\text { risk }\end{array}$ & $\begin{array}{c}\text { Moderate } \\
\text { Risk }\end{array}$ & \\
\hline Well nourished & 2 & 2 & 1 & 5 \\
\hline Risk of malnutrition & 1 & 12 & 3 & 16 \\
\hline Malnutrition & 1 & 7 & 1 & 9 \\
\hline Total & 4 & 21 & 5 & 30 \\
\hline
\end{tabular}

Note: Fisher's Exact test: $P=0.377$

Regarding energy intake, $40 \%(n=12)$ of the patients presented adequate consumption, according to the recommendations of the Dietary Reference Intakes (DRIs). The distribution of this intake between the degrees of risk for dysphagia can be seen in Figure 1. There was no association between caloric intake and the risk of dysphagia $(p=0.853)$ according to Fisher's Exact test. Similarly, there was no statistical difference between caloric intake and the different degrees of dysphagia $(p=0.754)$ according the Kruskal Wallis test. Therefore, caloric intake was similar among the patients, regardless of risk of dysphagia.

Considering the recommended protein volumes (in grams) for gender and age, some patients were found to have inadequate consumption (Table 4). The mean protein intake was $1.2 \mathrm{~g} / \mathrm{kg} /$ day, however, $23.3 \%(\mathrm{n}=7)$ of the patients consumed less than the recommended volume $(0.8 \mathrm{~g} / \mathrm{kg} /$ day $)$.

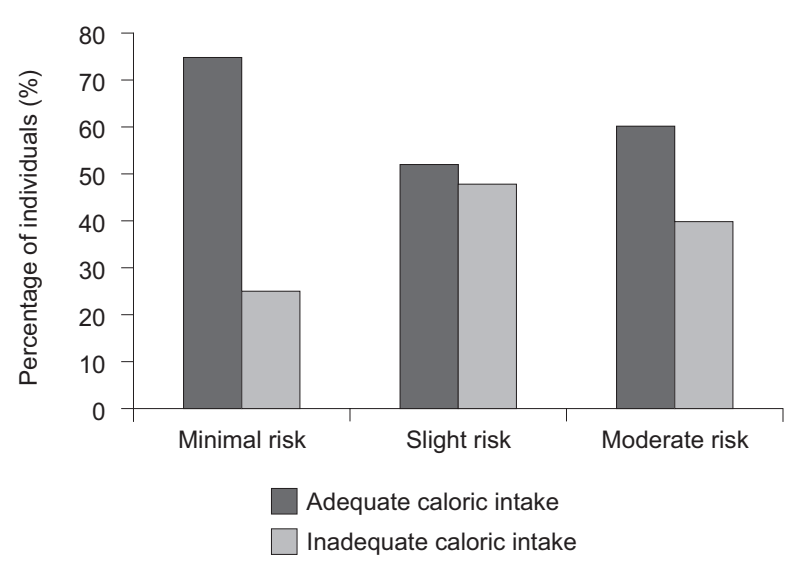

No difference or association was found between caloric intake and risk of dysphagia using the Kruskal Wallis test $(p=0.754)$ and Fisher's Exact test $(p=0.853)$, respectively

Figure 1 - Caloric intake of patients with Alzheimer's disease with different degrees of risk of dysphagia, Guarapuava, PR, Brazil, 2011.

According to the DRI recommendation, carbohydrates should represent 45 to $65 \%$ of the energy from the diet. However, $26.6 \%(n=8)$ of the subjects consumed less than $45 \%$, while $10 \%(n=3)$ consumed more than $65 \%$.

Among the micronutrients assessed, folate, copper and magnesium were inadequately consumed by all the patients, with percent standards below those recommended. Iron and sodium presented the lowest 
percentages of individuals with inadequate intakes. Micronutrient intake was found to be inadequate in all the patients. Regarding the percent standard, copper was the micronutrient with a lowest percentage, while the intake of vitamin B12 was the closest to adequate (Table 4).

Table 4 - Average recommendation of percent standard and the percentage of patients with inadequate intake of nutrients consumed by patients with Alzheimer's Diesease, Guarapuava, PR, Brazil, 2011

\begin{tabular}{|c|c|c|c|c|}
\hline Nutrient & $\begin{array}{c}\text { Intake } \\
\text { (mean } \pm S D)\end{array}$ & Recommendation* & $\begin{array}{l}\text { Percent } \\
\text { standard }^{\dagger}\end{array}$ & $\begin{array}{l}\text { Patients with inadequate intake } \\
\mathrm{n}(\%)\end{array}$ \\
\hline Proteins (g) & $74.7 \pm 37.9$ & $46-56$ & $148.4 \pm 72.4$ & $8(26.6)$ \\
\hline Carbohydrates (g) & $211.1 \pm 93.0$ & 130 & $162.4 \pm 71.5$ & $5(16.6)$ \\
\hline Lipids (g) & $53.8 \pm 29.3$ & $\mathrm{ND}^{\ddagger}$ & - & - \\
\hline Vitamin A (RE) & $510.0 \pm 533.8$ & $700-900$ & $64.6 \pm 65.3$ & $22(73.3)$ \\
\hline Vitamin D (mcg) & $2.9 \pm 2.7$ & $10-15$ & $21.5 \pm 19.7$ & $29(96.6)$ \\
\hline Vitamin B1 (mg) & $1.5 \pm 0.8$ & $1.1-1.2$ & $134.1 \pm 70.8$ & $8(26.6)$ \\
\hline Vitamin B2 (mg) & $1.3 \pm 0.6$ & $1.1-1.3$ & $117.7 \pm 55.4$ & $8(26.6)$ \\
\hline Vitamin B3 (mg) & $25.6 \pm 30.2$ & $14-16$ & $169.5 \pm 189.9$ & $19(63.3)$ \\
\hline Vitamin B5 (mg) & $2.8 \pm 1.3$ & 5 & $56.2 \pm 26.2$ & $28(93.3)$ \\
\hline Vitamin B6 (mg) & $1.1 \pm 0.7$ & $1.5-1.7$ & $70.8 \pm 48.9$ & $23(76.6)$ \\
\hline Vitamin B12 (mcg) & $6.7 \pm 12.3$ & 2.4 & $282.4 \pm 513.5$ & $13(43.3)$ \\
\hline Vitamin C (mg) & $65.9 \pm 65.6$ & $75-90$ & $81.5 \pm 84.6$ & $19(63.3)$ \\
\hline Vitamin E (mg) & $15.7 \pm 12.6$ & 15 & $104.7 \pm 84.0$ & $26.6(8)$ \\
\hline Folate (mcg) & $122.5 \pm 63.3$ & 400 & $30.6 \pm 15.8$ & $30(100)$ \\
\hline Calcium (mg) & $479.2 \pm 296.6$ & 1200 & $39.9 \pm 24.7$ & $29(96.6)$ \\
\hline Phosphorus (mg) & $886.4 \pm 398.5$ & 700 & $126.6 \pm 56.9$ & $8(26.6)$ \\
\hline Magnesium (mg) & $167.4 \pm 67.5$ & $320-420$ & $46.3 \pm 17.3$ & $30(100)$ \\
\hline Iron (mg) & $2.65 \pm 6.9$ & 8 & $158.1 \pm 87.0$ & $5(16.6)$ \\
\hline Zinc (mg) & $9.4 \pm 6.6$ & $8-11$ & $103.2 \pm 66.0$ & $16(53.3)$ \\
\hline Copper (mcg) & $1.4 \pm 3.2$ & 900 & $0.16 \pm 0.35$ & $30(100)$ \\
\hline lodine(mcg) & $53.5 \pm 36.0$ & 150 & $35.6 \pm 23.9$ & $29(96.6)$ \\
\hline Selenium (mcg) & $60.6 \pm 36.0$ & 55 & $110.2 \pm 65.5$ & $14(46.6)$ \\
\hline Manganese (mg) & $1.9 \pm 1.9$ & $1.8-2.3$ & $94.7 \pm 84.3$ & $21(70)$ \\
\hline Potassium (mg) & $2404.6 \pm 3450.5$ & 4700 & $51.1 \pm 73.4$ & $29(96.6)$ \\
\hline Sodium (mg) & $2152.3 \pm 1153.5$ & $1200-1300$ & $177.1 \pm 96.3$ & $5(16.6)$ \\
\hline
\end{tabular}

*Recommendation: Institute of Medicine (IOM) / Food and Nutrition Board (FNB) - 1997, 1998, 2000, 2001, 2005 - according to age and gender of the patient +Percent standard: nutrient intake / recommendation for sex and age x 100

¥ND: Value not established

\section{Discussion}

In this study, it was found that the patients with $A D$ exhibited an increased risk of dysphagia with increased severity of $A D$, demonstrating the relationship between these two conditions. The CDR1 group presented the highest levels of swallowing, while the individuals in the CDR2 and CDR3 groups were distributed between levels of impairment, from mild to moderate, while the CDR3 group presented a higher percentage in the moderate state. These results corroborate previous studies that, using different methodologies, have shown that swallowing disorders correlate with the severity of the dementia, however, unlike the previous studies the present study found that patients in CDR1 already present a slight risk of developing dysphagia(9), this is important because it highlights the need for monitoring this aspect from the onset of the dementia or cognitive deficit.

One study evaluated functional changes in the cortical control of swallowing in patients with mild $A D$ and found that in these patients the cortical response traditionally involved in swallowing was significantly lower than the controls in many cortical areas. This finding suggests that changes in the cortical contro of swallowing may begin long before the dysphagia becomes apparent. This finding may be related to the AD-related pathological alterations in the brain that emerge years or decades before the first symptoms are diagnosed $^{(19)}$.

Unlike previous studies(20-21), the present study found no association between risk of dysphagia and 
nutritional status. One possible explanation is that the process of malnutrition may be slower to evolve than the dysphagia, and also may not only be related to the risk of development of dysphagia. Furthermore, no patients were found to be in the severe stage of dysphagia, at which point this relationship could possibly be more evident. Another factor to consider is that generally, elderly people choose foods that are high in calories, of little nutritional value, however, are easy to chew and swallow(22).

The caloric and macronutrient intake in the assessed patients was within the parameters of adequacy in most of the individuals. These data corroborate other authors that show that weight reduction can be found in patients with $A D$ in spite of their adequate energy intake. It is not known exactly what causes weight loss in patients with $A D$, however, several hypotheses have been proposed to explain this phenomenon, such as Mesial Temporal Cortex (CTM) atrophy, which is involved with diet; increased energy needs; and organic disorders ${ }^{(11)}$. It is believed that behavioral disorders may also play a part(23).

Conversely, a high percentage of patients presented an inadequate intake of micronutrients. It is important to consider that the brain is known to be susceptible to oxidative stress, since it is rich in polyunsaturated fatty acids, as well as having high mitochondrial activity that favors the production of reactive oxygen species. Oxidative stress appears to play an important role in the pathology of $A D$, and the present study found that the levels of consumption of antioxidants, such vitamins $A$, $C, E$ and selenium, were inadequate in the AD patients evaluated. Cohort studies indicate that the risk of $A D$ is reduced in individuals with diets that include a high or supplementary intake of antioxidant vitamins such as tocopherol (vitamin E) and ascorbic acid

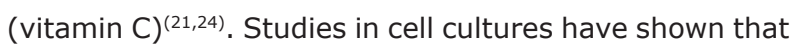
vitamins $E$ and $C$ can inhibit $A \beta$ protein deposition(25), neuronal cell death and apoptosis( ${ }^{(26)}$. Selenium also presents an important antioxidant role and is considered to be a protective agent from damage caused by free radicals ${ }^{(27)}$. Therefore, it is important to monitor the consumption of these substances, since they can act as neuroprotective factors, preventing or slowing the progress of $A D$.

In addition to the inadequate intake of antioxidants, intake of vitamin B12, folate and zinc was suboptimal in the patients evaluated in this study. This is troubling, since vitamin B12 deficiency can lead to dementia that is similar in clinical presentation to Alzheimer's dementia but that can be reversed by supplementing this vitamin(28). Folate, in turn, is necessary in the synthesis of S-adenosylmethionine (SAMe), a provider of methyl to various important brain biomolecules, such as phospholipids, neurotransmitters, amino acids and nucleic acids $^{(29)}$. Low serum levels of folate are associated with structural and functional changes in the brain, and also with atrophy of the cerebral cortex, and dementia. Folate supplementation has been shown to have a positive effect on cognitive functions and memory deficits ${ }^{(30)}$. Apart from vitamin B12 and folate, zinc plays a critical role in neurotransmission in the glutamatergic synapses. It is in the glutamatergic synapses that the amyloid pathology in AD starts, and they contain high concentrations of zinc, which is released during neurotransmission(31).

These problems with the nutritional status, weight loss, and inadequate intake of nutrients observed in the elderly people with AD, highlight the importance of nutritional care and interventions regarding mealtime difficulties, a aspect relevant to the clinical nursing practice with $A D$ patients ${ }^{(13-14)}$.

\section{Conclusion}

In conclusion, the results of this study suggest there is an association between the risk of dysphagia and the stage of $A D$, however, not between the risk of dysphagia and the nutritional status nor the caloric intake. The results indicate the need to monitor the micronutrient intake in patients with $A D$, as high levels of inadequate intake of micronutrients were found, which is known to be related to important brain functions. More studies are necessary, using a larger sample, considering that this is the main limitation of this study.

\section{Acknowledgments}

We thank Bárbara Fermino and Kaílla Gonçalves for help during the home visits and data collection.

\section{References}

1. United Nations. World Population Prospects: The 2006 Revision. New York: United Nations; 2010.

2. Apostolova LG, Thompson PM. Mapping progressive brain structural changes in early Alzheimer's disease and mild cognitive impairment. Neuropsychologia. 2008;46(6):1597-612.

3. Brookmeyer R, Johnson E, Ziegler-Graham K, Arrighi HM. Forecasting the global burden of Alzheimer's disease. Alzheimer's Dementia. 2007;3(3):186-91. 
4. Corrada MM, Brookmeyer R, Berlau D, Paganini-Hill A, Kawas $\mathrm{CH}$. Prevalence of dementia after age 90: results from the 90+ study. Neurology. 2008;71(5):337-43.

5. Ballard C, Gauthier S, Corbett A, Brayne C, Aarsland D, Jones E. Alzheimer's disease. Lancet. 2011;377(9770):1019-31.

6. Horner J, Alberts MJ, Dawson DV, Cook GM. Swallowing in Alzheimer's disease. Alzheimer Dis Assoc Disorders. 1994;8(3):177-89.

7. Priefer BA, Robbins J. Eating changes in mildstage Alzheimer's disease: a pilot study. Dysphagia. 1997;12(4):212-21.

8. Muñoz AM, Agudelo GM, Lopera FJ. Diagnóstico del estado nutricional de los pacientes con demencia tipo Alzheimer registrados en el grupo de neurociencias, Medellín. Biomedica. 2006;26(1):113-25.

9. Wada H, Nakajoh K, Satoh-Nakagawa T, Suzuki $T$, Ohrui $T$, Arai $H$, et al. Risk factors of aspiration pneumonia in Alzheimer's disease patients. Gerontology. 2001;47(5):271-6.

10. Seth R. Weight loss in Alzheimer's disease. Int J Geriatr Psychiatry. 1994;9:605-20.

11. Gillette-Guyonnet $S$, Nourhashemi F, Andrieu S, de Glisezinski I, Ousset PJ, Riviere D, et al. Weight loss in Alzheimer disease. Am J Clin Nutr. 2000;71(2):637S-42S. 12. Cronin-Stubbs D, Beckett LA, Scherr PA, Field TS, Chown MJ, Pilgrim DM, et al. Weight loss in people with Alzheimer's disease: a prospective population based analysis. BMJ. 1997;314(7075):178-9.

13. Liu W, Cheon J, Thomas SA. Interventions on mealtime difficulties in older adults with dementia: A systematic review. Int J Nurs Stud. 2013;PII: S00207489(12)00463-4.

14. Jyvakorpi SK, Puranen T, Pitkala KH, Suominen MH. Nutritional treatment of aged individuals with Alzheimer disease living at home with their spouses: study protocol for a randomized controlled trial. Trials. 2012;13:66.

15. McKhann G, Drachman D, Folstein M, Katzman R, Price D, Stadlan EM. Clinical diagnosis of Alzheimer's disease: report of the NINCDS-ADRDA Work Group under the auspices of Department of Health and Human Services Task Force on Alzheimer's Disease. Neurology. 1984;34(7):939-44

16. Morris JC. The Clinical Dementia Rating (CDR): current version and scoring rules. Neurology. 1993;43(11):2412-4.

17. Maciel JR, Oliveira CJV, Tada CMP. Associação entre risco de disfagia e risco nutricional em idosos internados em hospital universitário de Brasília. Rev Nutr. $2008 ; 21(4): 411-21$.
18. Vellas B, Villars $H$, Abellan $G$, Soto $M E$, Rolland $Y$, Guigoz Y, et al. Overview of the MNA - Its history and challenges. J Nutr Health Aging. 2006;10(6):456-63; discussion 63-5.

19. Humbert IA, McLaren DG, Kosmatka K, Fitzgerald M, Johnson S, Porcaro E, et al. Early deficits in cortical control of swallowing in Alzheimer's disease. JAD. 2010;19(4):1185-97

20. Alagiakrishnan K, Bhanji RA, Kurian M. Evaluation and management of oropharyngeal dysphagia in different types of dementia: a systematic review. Arch Gerontol Geriatr. 2013;56(1):1-9.

21. Morris MC, Evans DA, Bienias JL, Tangney CC, Bennett DA, Aggarwal $N$, et al. Dietary intake of antioxidant nutrients and the risk of incident Alzheimer disease in a biracial community study. JAMA: the journal of the American Medical Association. 2002;287(24):3230-7.

22. Freitas AMDP, Philippi ST, Ribeiro SML. Listas de alimentos relacionadas ao consumo alimentar de um grupo de idosos: análises e perspectivas. Rev Bras Epidemiol. 2011;14(1):161-77.

23. White HK, McConnell ES, Bales CW, Kuchibhatla M. A 6-month observational study of the relationship between weight loss and behavioral symptoms in institutionalized Alzheimer's disease subjects. J Am Med Dir Assoc. 2004;5(2):89-97.

24. Van Gelder BM, Buijsse B, Tijhuis $M$, Kalmijn $S$ Giampaoli S, Nissinen $A$, et al. Coffee consumption is inversely associated with cognitive decline in elderly European men: the FINE Study. European J Clin Nutr. 2007;61(2):226-32.

25. Butterfield DA, Koppal T, Subramaniam R, Yatin S. Vitamin $E$ as an antioxidant/free radical scavenger against amyloid beta-peptide-induced oxidative stress in neocortical synaptosomal membranes and hippocampal neurons in culture: insights into Alzheimer's disease. Rev Neurosci. 1999;10(2):141-9.

26. Huang J, May JM. Ascorbic acid protects SH-SY5Y neuroblastoma cells from apoptosis and death induced by beta-amyloid. Brain Res. 2006;1097(1):52-8.

27. Gao S, Jin Y, Hall KS, Liang C, Unverzagt FW, Ji R, et al. Selenium level and cognitive function in rural elderly Chinese. Amn J Epidemiol. 2007;165(8):955-65.

28. Ramesh BN, Rao TS, Prakasam A, Sambamurti K, Rao KS. Neuronutrition and Alzheimer's disease. JAD. 2010;19(4):1123-39.

29. Bottiglieri T, Laundy M, Crellin R, Toone BK, Carney MW, Reynolds EH. Homocysteine, folate, methylation, and monoamine metabolism in depression. J Neurol Neurosurgery Psychiatry. 2000;69(2):228-32. 
30. Tettamanti M, Garri MT, Nobili A, Riva E, Lucca U. Low folate and the risk of cognitive and functional deficits in the very old: the Monzino 80-plus study. J Am College Nutr. $2006 ; 25(6): 502-8$.

31. Crouch PJ, White AR, Bush AI. The modulation of metal bio-availability as a therapeutic strategy for the treatment of Alzheimer's disease. FEBS J. 2007;274(15):3775-83. 